\title{
The estimation of competitive positions of non-steroid anti- inflammatory drugs on pharmaceutical market of Ukraine
}

Abstract The aim of our analysis is the estimation of non-steroid anti-inflammatory drugs (NSAID) competitiveness level, calculation of capacity, share and saturation of studied segment of market that allow to improve the competitive strategies of pharmaceutical manufacturing enterprises.

MATERIALS AND METHODS: According to the results of content-analysis of foreign and native economic literature, we elaborated the methodology of estimation of NSAID competitive positions that consists of six main stages. The offered model of estimation of competitiveness of the studied group of medicines is based on the construction of competition map of medicines on the example of non-selective NSAID as the largest group by the number of presented trade names (TN) using the calculation of market share of medicines for 2015-2016 and dynamics of its growth.

RESULTS: The results of NSAIDTN distribution in groups according to the market share volume testify that only 8 TN of medicines among 74 are the leaders of market and 10 TN are characterized with strong competitive position. At the same time 51 NSAID TN are outsiders and 5 TN have weak competitive position.

The results of NSAID TN distribution in groups according to the change of their competitive position allow state that 16 TN among 74 have fast worsening competitive position, 43 TN belong to the group with worsening competitive position and only 5 TN has competitive position, characterized by fast improvement.

CONCLUSION: The analysis of position, occupied by NSAID TN in matrix, demonstrated that 8 TM of medicines are the leaders of the market. At the same time 51 medicines TN are outsiders. The results of research demonstrated that 59 NSAID TN are characterized with worsening and fast worsening competitive positions.

Keywords pharmaceutical market-non-steroid anti-inflammatory drugs-market share-competition map

\section{INTRODUCTION}

One of the most important indicators of effectiveness of enterprise activity that determines the success of work, financial status and position of an enterprise in the market is the competitiveness of pharmaceutical products (Dolzhansky \& Zagorna, 2006).

The competitiveness of each commodity in the market is determined by the totality of many factors and is considered as an advantage of this commodity as compared with the others (of analogous importance). The competitiveness of medicines is determined by the totality of different characteristics that determine their comparative positions in the market.

Under the conditions of rigid competitive environment that has been formed in the native market of medicines, the urgent and timely acceptance of managerial-productive decisions, directed on the search and mastering of prospective market niches, formation of competitive positions and unique advantages of medicines, coordination of assortment-selling strategies are the determinative components of successful activity of pharmaceutical firms, enterprises and organizations (Levy \& Weitz, 2004; Kotler \& Keller, 2006; Kotvitska \& Kostiuk, 2016).

Thus, the aim of our analysis is the estimation of non-steroid anti-inflammatory drugs' (NSAID) competitiveness level, calculation of capacity, share and saturation of studied segment of market that allow to improve the competitive strategies of pharmaceutical manufacturing enterprises.

\section{MATERIALS AND METHODS}

According to the results of content-analysis of foreign and native economic literature, we elaborated the methodology of estimation of NSAID competitive positions that consists of six main stages, including the succession of arrangements at each stage and the use of correspondent effective indices (Fig. 1) (Berman \& Telen,2004; Dzhuparova et al., 2010; Kaune, 2005; Mnushko et al., 2009).

*E-mail:volodymyr_kostiuk@ukr.net

( ) European Pharmaceutical Journal 
The offered model of estimation of competitiveness of the studied group of medicines is based on the construction of competition map of medicines, on the example of nonselective NSAID as the largest group by the number of presented trade names (TN), using the calculation of market share of NSAID for 2015-2016 and the dynamics of its growth.

The first stage includes the analysis of assortment and determination of modern tendencies of NSAID market formation.

It is necessary to note that the methodological base of estimation of competitive positions in the market share. That is why, the second stage provides the estimation of competitive situation on NSAID market, realized by calculation of the market share of each formulation of the presented TN of studied segment of medicines. Thus, the calculation of market share for each NSAID TN was carried out according to the formula 1 (Berman \&Telen,2004):

$$
D_{i}=\frac{T_{i}}{T_{g e n .}} \times 100 \%
$$

where, $D$ - market share of i-th TN NSAID, \% $T_{i}$ - sales volume for i-th TN NSAID in DDDs sold per year $T_{\text {gen. }}$ - general volume of NSAID sales in DDDs sold per year.

Depending on the volume of market share, medicines can be leader or outsider in the market. To differentiate the groups of medicines - outsiders, medicines with weak, strong competitive position and leaders of the market., within the third stage, it is necessary to determine the mean-square deviation of NSAID TN market share and also its minimal, maximal and mean arithmetical value. Thus, we realized the determination of limits of classification groups of studied NSAID using the law of variation of individual values of sign ('three-sigma rule').

The directions of fourth stage of methodology that are the estimation of NSAID competitive positions provide determination of dynamics of growth, mean value and dispersion of dynamics of growth of NSAID TN market share. Thus, the calculation of mean dynamics of the market share growth for each formulation of medicines TN for the studied period (2016) relative to the base period (2015) and its meansquare deviation was realized according to the formula 2 (Burtseva et al., 2005):

$T_{i}=\frac{D_{i}-D_{0}}{D_{0}} \times 100 \%$

where, $T_{i}$ - dynamics of growth of market share of i-th NSAID $\mathrm{TN}, \%$

$\mathrm{Di}$ - market share of i-th TN in the studied period, \% $D_{0}$ - market share of i-th TN in the base period, $\%$.

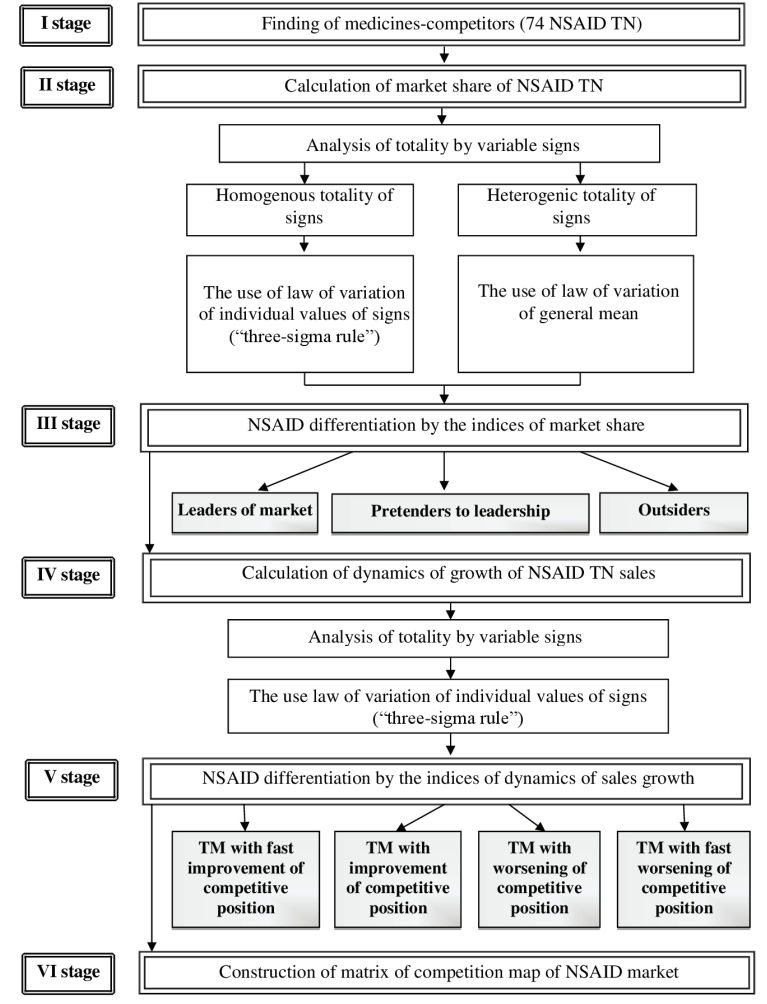

Figure 1. The methodology of estimation of NSAID competitive positions on pharmaceutical market of Ukraine

The estimation of medicines' competitive positions within the chosen NSAID segment is the fifth stage of offered methodology that is expedient to be realized for the revelation of prospective market niches for elaboration of medicines and introducing them in production. For the estimation of degree of change of competitive position of the studied medicines, we separated four groups of medicines by the dynamics of their marker share growth (Mnushko et al., 2009):

- medicines with fast improvement of competitive position;

- medicines with improvement of competitive position;

- medicines with worsening of competitive position;

- medicines with fast worsening of competitive position.

At the sixth stage, the matrix of competition map of the market is constructed, taking into account the received results of estimation of the market share distribution and degree of change of competitive position of the studied NSAID TN. It is based on the cross classification of NSAID TN by the indices of market share and its dynamics, as a result of which, we use the 16 types of strategic positions of medicines that differ by the degree of use of competitive advantages and potential possibility to resist the competitors' pressure are determined (Mnushko et al., 2009). The competition map of medicines allows us to determine their status and systematize the competitive advantages. 
Table 1. The criteria of reference of TN of non-selective NSAID to classification groups

\begin{tabular}{|c|c|c|c|c|}
\hline $\begin{array}{c}\text { Classification } \\
\text { groups }\end{array}$ & $\begin{array}{c}\text { Formulas of calculation of } \\
\text { classification groups limits, } \%\end{array}$ & $\begin{array}{c}\text { Results of calculation of } \\
\text { market limits }\end{array}$ & Characteristic & $\begin{array}{c}\text { Number of } \\
\text { NSAID TN }\end{array}$ \\
\hline I & $D_{\text {max }} ; D_{\text {mean }}+3 \times \sigma_{2} / \sqrt{n}$ & $15.19 ; \ldots 2.69$ & TN - leaders of market & 8 \\
\hline II & $D_{\text {mean }}+3 \times \sigma_{2} / \sqrt{ } ; D_{\text {mean }}$ & $2.69 ; \ldots 1.35$ & $\begin{array}{c}\text { TN with strong competi- } \\
\text { tive position }\end{array}$ & 10 \\
\hline III & $D_{\text {mean }} D_{\text {mean }}-3 \times \sigma_{1} / \sqrt{n}$ & $1.35 ; \ldots 1.20$ & $\begin{array}{c}\text { TN with weak competitive } \\
\text { position }\end{array}$ & 5 \\
\hline IV & $D_{\text {mean }}-3 \times \sigma_{1} / \sqrt{n} ; D_{\text {min }}$ & $1.20 ; \ldots 0.00^{*}$ & TN - outsiders & 51 \\
\hline
\end{tabular}

*the absolute value is 0.00002

Table 2. The results of estimation of the degree of change of NSAID TN competitive positions

\begin{tabular}{|c|c|c|c|c|}
\hline $\begin{array}{l}\text { Classification } \\
\text { groups }\end{array}$ & $\begin{array}{l}\text { Formulas of calculation of } \\
\text { classification groups limits \% }\end{array}$ & $\begin{array}{l}\text { Results of calculation of } \\
\text { market limits }\end{array}$ & Characteristic & $\begin{array}{l}\text { Number of } \\
\text { NSAID TN }\end{array}$ \\
\hline 1 & $T_{\text {max }} \cdot T_{\text {mean }}+3 \times \sigma / \sqrt{ } n$ & $1579.32 ; \ldots 92.03$ & $\begin{array}{l}\text { TN with fast improvement } \\
\text { of competitive position }\end{array}$ & 5 \\
\hline II & $T_{\text {mean }}+3 \times \sigma / \sqrt{ } n ; T_{\text {mean }}$ & $92.03 ; \ldots 21.91$ & $\begin{array}{l}\text { TN with improvement of } \\
\text { competitive position }\end{array}$ & 10 \\
\hline III & $T_{\text {mean }} \cdot T_{\text {mean }}-3 \times \sigma / \sqrt{ } n$ & $21.91 ; \ldots-48.21$ & $\begin{array}{l}\text { TN with worsening of com- } \\
\text { petitive position }\end{array}$ & 43 \\
\hline IV & $T_{\text {mean' }} \cdot T_{\text {mean }}-3 \times \sigma / \sqrt{ } n$ & $-48.21 ; \ldots-99.93$ & $\begin{array}{l}\text { TN with fast worsening of } \\
\text { competitive position }\end{array}$ & 16 \\
\hline
\end{tabular}

\section{RESULTS}

At the first stage of the offered methodology, according to the results of the data of Public register of medicines, which includes all medicines approved for marketing by the Ministry of Health of Ukraine, it was established that NSAID assortment is presented by 13 pharmacotherapeutic groups: M01AB01 - indometacin, M01AB05 - diclofenac, M01AB15 - ketorolac, M01AB16 - aceclofenac, M01AC01 - piroxicam, M01AC02 - tenoxicam, M01AE01 - ibuprofen, M01AE02 naproxen, M01AE03 - ketoprofen, M01AE09 - flurbiprofen, M01AE14 - dexibuprofen, M01AE17 - dexketoprofen, M01AG01 - mefenamic acid (Ministry of Health of Ukraine, 2015).

The analysis at the second stage included 74 TNs of medicines, divided into 2 sectors in correspondence with the occupied share. The first sector included medicines, for which the market share was more than the mean arithmetic value of market shares of the studied NSAID; the other one united medicines, for which the market share was less than the mean arithmetic value (1.35\%).

Thus, the first sector was formed of 18 NSAID TNs with mean volume of market share $4.51 \%$, and other 56 TNs with mean volume of market share $0.34 \%$.

Within the third stage, the calculations of mean-square deviation of NSAID TN market share, that in totality with minimal and maximal values allows us to make distribution of the studied medicines in 4 classification groups, were realized in each sector (Table1).
The results of NSAID TN distribution in groups according to the market share volume testify that only 8 TNs of medicines among 74 are the leaders of market and 10 TNs are characterized with strong competitive position. At the same time, 51 NSAID TNs are outsiders and 5 TNs have weak competitive positions.

It is well-known that the estimation of tendencies of change of competitive position is realized using the index of mean dynamics of market share growth. Thus, the calculated mean dynamics of growth of the studied NSAID segment is $21.91 \%$ (the fourth stage of methodology).

NSAIDTN classification by the degree of change of competitive position is presented in Table 2 (the fifth stage of offered methodology).

The results of NSAIDTN distribution in groups according to the change of their competitive position allow us to state that 16 TNs among 74 have fast worsening competitive position, 43 TNs belong to the group with worsening competitive position and only 5 TNs have competitive position, characterized by fast improvement.

The received results of estimation of distribution of market share and the degree of change of competitive position of the studied NSAID TN allowed us to construct the matrix of competition map of the market (Table 3) within the sixth stage of methodology.

The results of analysis of NSAID TN position on the competitive map testifies that among the studied segment of medicines, 7 TN-leaders are characterized by worsening 
Table 3. The matrix of formation of competition map of the native market of NSAID

\begin{tabular}{|c|c|c|c|c|}
\hline $\begin{array}{l}\begin{array}{c}\text { Classification of groups } \\
\text { by the market share }\end{array} \\
\text { NSAID TNgroup by } \\
\text { the change of market share }\end{array}$ & $\begin{array}{l}\text { TN - leaders } \\
\text { of market }\end{array}$ & $\begin{array}{l}\text { TN with strong } \\
\text { competitive position }\end{array}$ & $\begin{array}{c}\text { TN with weak } \\
\text { competitive position }\end{array}$ & TN - outsiders \\
\hline $\begin{array}{l}\text { Fast improvement of competitive } \\
\text { position }\end{array}$ & --- & --- & --- & 5 NSAID TN \\
\hline Improvement of competitive position & 1 NSAID TN & 3NSAIDTN & --- & 6 NSAIDTN \\
\hline Worsening of competitive position & 7 NSAID TN & 7 NSAID TN & 5NSAIDTN & 24NSAID TN \\
\hline Fast worsening of competitive position & --- & --- & --- & 16NSAIDTN \\
\hline
\end{tabular}

competitive position; 1 TN-leader has competitive position, characterized by improvement; 3 TNS that pretend to leadership have improving competitive position; 12 TNs that pretend to leadership have worsening competitive position; 5TN-outsiders have fast improving competitive position; 6 TN-outsiders have improving competitive position; 24 TNoutsiders are characterized with worsening competitive position; and16 TN-outsiders have fast worsening competitive position.

\section{DISCUSSION}

Inmodern practice ofapplied marketing research, considerable attention is paid to the analysis of market environment. The study of market processes involves determining the dynamics of market conditions. Each company faces the task of assessing its own competitiveness, which is due to the quality management of supply processes. The most important for enterprises are the indicators that reflect the dynamics of consumption of goods, the volume of wholesale and retail trade. Also, in the conditions of limited information for manufacturers, it is relevant to calculate the capacity and market share, to assess the level of competitiveness of products.

The results of the conducted research provide comprehensive and reliable information on both the dynamics of pharmaceutical market and trends in its structural segments, trademarks. Using the obtained results, the manufacturing companies are able to monitor market conditions, its capacity and development trends. Also, it is possible to conduct market segmentation by commodity and market characteristics to conduct their comparative analysis. Searching market niches and choice of perspective directions of optimization of commercial policy; conducting competitive analysis and establishing market segments with the lowest competitive activity becomes more reasonable and appropriate.

Thus, the competitive map of medicines serves to determine their status and to systematize their competitive advantages. In 2016, in the Ukrainian market of NSAIDs, there is a situation where there are no TN-leaders of market and TN that pretend to leadership with rapid improvement of the competitive position.
The offered methodology of estimation of NSAID competitive positions, fromourpoint ofview, can beused by pharmaceutical enterprises for choosing the grounded approaches to elaboration of competitive strategy, preventing the negative tendencies in production-selling processes of enterprises. The received results that are the real reproduction of the modern market situation, allow enterprises to determine the features of development of competitive situation on the market and to reveal the closest competitors.

For manufacturers of medicines-leaders of market, according to the market share, the main directions of competition strategies are the stabilization of competitive position by maintaining the achieved level of profitability and by creating a more flexible pricing policy.

In order to achieve competitiveness, the following strategic alternatives are recommended for the manufacturers of medicines with a strong competitive position: search for a vacant niche with weak competition, adapting to the selected target market, following the behaviour of the leader.

Manufacturers of medicines with weak competitive position must focus on reducing the cost of medicines.

The position of medicines-outsiders of the investigated segment of the market requires pharmaceutical companies to reorganize their marketing strategies (with a significant reduction in costs or, conversely, an increase in the medicine prices in the case of inelastic demand).

\section{LIMITATIONS OF RESEARCH}

Market researches on the competitiveness in pharmacy on various thematic areas of competitive analysis are widely represented in the scientific works of Ukrainian scientists. But detailed analysis of publications shows that mainly the competitiveness of manufacturing companies, pharmacies and limited analysis of the competitive advantages of medicines were investigated.

At the same time, the lack of available state statistical information on sales volumes makes it impossible to carry out a full-fledged analysis of the market situation in the domestic pharmaceutical market, which determines the use of special methods of calculation and additional sources of information. The additional sources of information include data on the 
intensity of goods consumption, information on primary and additional sales and information obtained from the results of the retail audit.

\section{CONCLUSIONS}

According to the results of NSAID TN differentiation by competitive position, it was established that 16 medicines among 74 have fast worsening competitive position, 43 TNs are included in the group with worsening competitive position and only 5 TNs have competitive position characterized with fast improvement.

The matrix of formation of competition map of the market, that is, an instrument of determination of status and competitive advantages, was constructed; the NSAID TN positions on the native pharmaceutical market were determined.
The analysis of position, occupied by NSAID TN in matrix, demonstrated that $8 \mathrm{TNs}$ of medicines are the leaders of the market. At the same time, 51 medicines TN are outsiders. The results of research demonstrated that 59 NSAID TNs are characterized with worsening and fast worsening competitive positions.

Thus, the obtained results are a real reproduction of the current market situation and allow developing a competition strategy more reasonably, to avoid or prevent the negative trends in the production and sales processes of the enterprises. Taking into account the obtained results, enterprises have the opportunity to operate information about the competitive status, to know the features of the development of a competitive situation on the market and to identify the closest competitors.

\section{References}

[1] Berman BS, Telen SP. A guide to developing and managing a wellintegrate multichannel retail strategy. International Journal of Retail Distribution Management. 2004;32:147-156.

[2] Burtseva TA, Sizov VS, Tsen OA. Marketing Management. Moscow; 2005:271.

[3] Dolzhansky IZ, Zagorna TO. The competitiveness of enterprises. Kyiv: Center of educational literature; 2006:384.

[4] Dzhuparova IA, Sboeva SG, Belova Yu V. Application of technologies of benchmarking for increasing the competitiveness of pharmacy organizations. Vestnik NSU. Series: Social and Economics Sciences. 2010;10(2 suppl):93-102.

[5] Kaune SB. Pharmacy Business Management. London: A Book LLC; 2005:367.

[6] Kotler F, Keller KL. Marketing Management. Express Course. St. Petersburg: Peter; 2006:464.
[7] Kotvitska AA, Kostiuk VH. Research of normative legal regulation of import substitution production of medicines in Ukraine. Management, Economics and Quality Assurance in Pharmacy. 2016;1(45suppl):85-89.

[8] Levy MM, Weitz BA. Retailing Management, Boston: McGraw Hill; 2004:532.

[9] Ministry of Health of Ukraine, Public register of medicines (http:// www.drlz.com.ua/) Accessed December 19, 2015.

[10] Mnushko ZN, Presnyakova VV, Rogulya OYu. Application of results of retail audit in the competitive analysis of the pharmaceutical market of Ukraine. Management, Economics and Quality Assurance in Pharmacy. 2009;2(4 suppl):44-48. 